\title{
Sudden back pain as clinical presentation of spontaneous spinal epidural hematoma
}

Dor lombar súbita como apresentação clínica de hematoma epidural espinhal espontâneo

Plinio Duarte Mendes', Clayton Lucas da Silva Lopes', Guilherme de Sousa Baptista², Paulo Mallard Scaldaferri ${ }^{3}$ Gustavo Agra Cariri ${ }^{1}$

An 89-year-old woman admitted to the Emergency Care Department with reported back pain nine days earlier that started suddenly when sitting. This subsequently evolved into progressive paraparesis (Frankel D). An MRI of the lumbosacral spine revealed an extensive lumbar epidural hematoma (Figure). The patient underwent decompressive laminectomy of T12-L1.
Spontaneous epidural hematoma is a rare disease, most often involving the thoracolumbar region, followed by the cervical region ${ }^{1}$. Non-traumatic causes include hypertension, coagulopathies, use of anticoagulants, arteriovenous abnormalities, tumors of the backbone and lumbar puncture. In approximately $40 \%$ of cases, the etiology cannot be determined. Typically, pain is the root of the acute onset, accompanied by neurological deficit ${ }^{1,2}$.
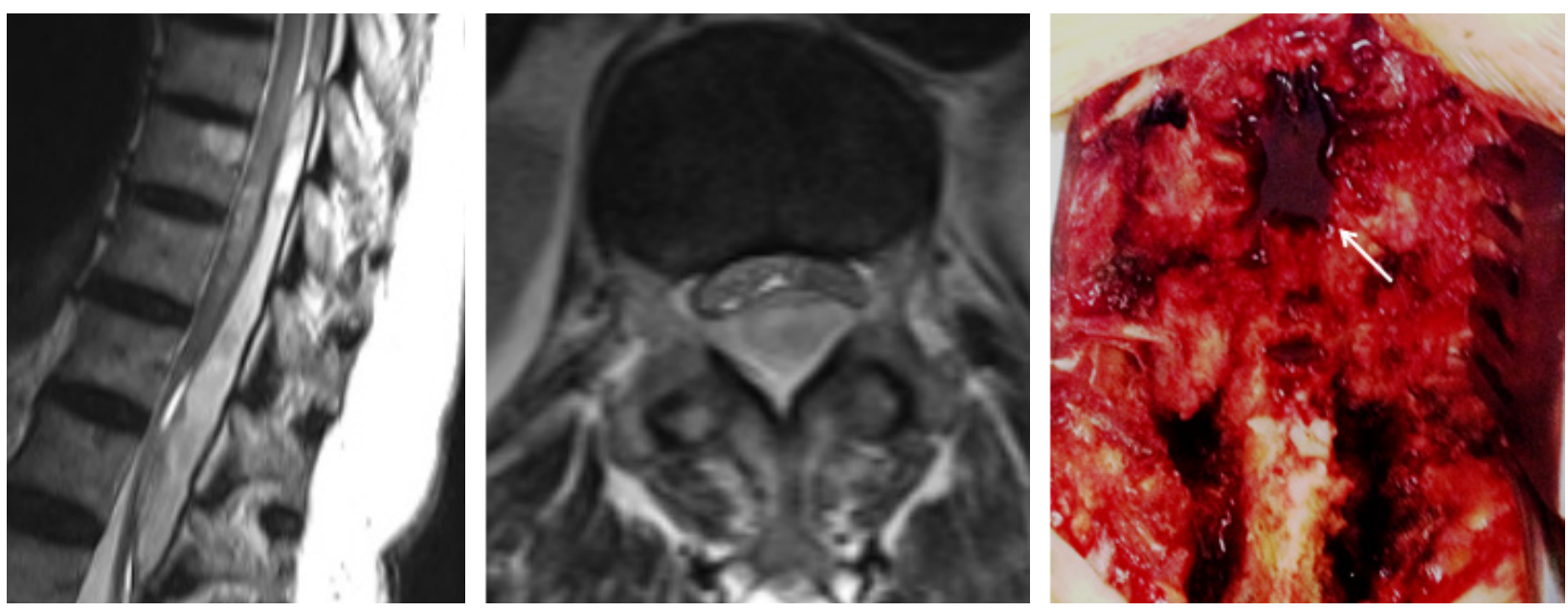

Figure. Sagittal and axial sequence. Epidural hematoma T5-T6 to L1-L2, more importantly in the T9-T10 to L1-L2 segment, which shows the compressive effect on the roots of the cauda equina, the thoracic spine and medullary conus. Bottom right: Intraoperative photograph showing the epidural hematoma after laminectomy (white arrow).

1. Liao CC, Hsieh PC, Lin TK, Lin CL, Lo YL, Lee SC. Surgical treatment of spontaneous spinal epidural hematoma: a 5-year experience. J Neurosurg Spine. 2009;11(4):480-6. doi:10.3171/2009.4.SPINE08904
2. Ferreira ROMF, Rocha FJ, Barros JA, Fonseca AVB, Paiva PR. [Spontaneous epidural hematoma of the lumbar region: report of two cases]. Arq Neuropsiquiatr. 1980;38(3):313-6. Portuguese. doi:10.1590/S0004-282X1980000300014

\footnotetext{
'Biocor Instituto, Departamento de Especialidades Cirúrgicas, Divisão de Neurocirurgia, Nova Lima MG, Brasil;

${ }^{2}$ Hospital São João de Deus, Divisão de Neurocirurgia, Divinópolis MG, Brasil;

${ }^{3}$ Hospital Unimed, Divisão de Neurocirurgia, Belo Horizonte MG, Brasil.

Correspondence: Plínio Duarte Mendes; Departamento de Especialidades Cirúrgicas, Serviço de Neurocirurgia, Biocor Instituto; R. da Paisagem, 280; 34000-000 Nova Lima MG, Brasil; E-mail: pliniou@hotmail.com

Conflict of interest: There is no conflict of interest to declare.

Received 25 July 2016; Accepted 09 September 2016.
} 